\title{
Use of sodium polyphosphates with different linear lengths in the production of spreadable processed cheese
}

\author{
G. Nagyová,, F. Buňka, ${ }^{* 1}$ R. N. Salek, ${ }^{*}$ M. Černíková, ${ }^{*}$ P. Mančík, ${ }^{*}$ T. Grůber,† and D. Kuchař† \\ *Department of Food Technology, Faculty of Technology, Tomas Bata University in Zlin, T. G. Masaryka 5555, 760 01, Zlin, Czech Republic \\ †Department of Research and Development, Fosfa PLC, Hraniční 268, 69141 Břeclav-Poštorná, Czech Republic
}

\begin{abstract}
The objective of this study was to describe the dependence of textural properties (hardness, cohesiveness, and relative adhesiveness) of processed cheese spreads on the proportion of disodium phosphate (DSP), tetrasodium diphosphate (TSPP), and sodium salts of polyphosphate in ternary mixtures of emulsifying salts. Sodium salts of polyphosphate with different mean lengths $(\mathrm{n} \approx 5,9,13,20$, and 28$)$ were used. Pentasodium triphosphate (PSTP) was used instead of TSPP in the second part of the study. Products with and without $\mathrm{pH}$ adjustment were tested (the target $\mathrm{pH}$ value was 5.60-5.80). Textural properties of the processed cheese were observed after 2, 9, and $30 \mathrm{~d}$ of storage at $6^{\circ} \mathrm{C}$. Hardness of the processed cheese with a low content of polyphosphate increased at a specific DSP:TSPP ratio $(\sim 1: 1$ to $3: 4)$. This trend was the same for all the polyphosphates used; only the absolute values of texture parameters were different. The same trends were observed in the ternary mixtures with PSTP, showing lower final values of hardness compared with samples containing TSPP. Hardness and cohesiveness decreased and relative adhesiveness increased in the samples with increased $\mathrm{pH}$ values and vice versa; the main trend remained unchanged.
\end{abstract}

Key words: processed cheese, emulsifying salt, polyphosphate, textural property

\section{INTRODUCTION}

Processed cheese can be characterized as a viscoelastic matrix, the basic material of which consists of cheeses at different stages of maturity. It is made by using a wide range of dairy (e.g., cream, butter, anhydrous milk fat, curd, milk powder, whey powder, caseinates) and nondairy ingredients and additives (e.g., hydrocolloids, coloring, sensory active mixtures), which are applied to modify the content (e.g., DM content, fat content, protein content) or functional properties of the product

Received July 1, 2013

Accepted September 22, 2013.

${ }^{1}$ Corresponding author: bunka@ft.utb.cz (e.g., firmness, meltability). Key components for the production of processed cheeses are emulsifying salts (ES), usually sodium salts of phosphates, polyphosphates, or citrates. The discontinuous production of processed cheeses includes (1) determining the composition of ingredients (with respect to the desired parameters of the final product); (2) placing the determined amounts of ingredients and additives into the melting device and the actual melting process (at a usual temperature of 85 to $105^{\circ} \mathrm{C}$ with a dwell time of several minutes); and (3) packaging in different wrapping materials (Guinee et al., 2004; Mizuno and Lucey, 2007).

The essential role of ES is the exchange of sodium ions for calcium ions in the casein matrix (gel) of the cheese; insoluble calcium paracaseinate changes into more soluble sodium paracaseinate, whose molecules (chains) can move within the melt system and thus enhance fat emulsification and water binding (Guinee et al., 2004; Shirashoji et al., 2006; Muslow et al., 2007). The ability of individual ES to support the exchange of sodium for calcium ions can vary. Generally, the ability to support ion exchange occurs in the following order (considering sodium salts): citrates $\approx$ monophosphates $<$ diphosphates $<$ triphosphates $<$ short polyphosphates $(<10$ phosphorus atoms in a molecule) $<$ long polyphosphates ( $>10$ phosphorus atoms in a molecule) (Guinee et al., 2004; Mizuno and Lucey, 2005a, 2007). El-Bakry et al. (2011) stated that citrates support ion exchange to a greater extent than monophosphates.

However, ES also affect the process of gel formation in the cooling matrix of the melt and thus enhance the formation of the final structure of the processed cheese. The process of forming the final matrix during cooling and subsequent storing is called creaming and it covers a wide range of different interactions: calcium bridges, disulfide bridges, hydrophobic interactions, electrostatic interactions, hydrogen bonds, calcium-phosphates complexes (bridges), and so on (Horne, 1998; Mizuno and Lucey, 2005a, 2007). Individual ES are able to influence gel formation in different ways. Diphosphates and triphosphates are considered to be substances directly supporting gel formation, and this is especially true when they are at an optimal concentration with respect to the other components in the mixture (Mizuno and 
Lucey, 2007; Buňka et al., 2013). According to Kaliappan and Lucey (2011) and Weiserová et al. (2011), specific interactions exist between monophosphates and diphosphates (at a ratio of approximately 1:1 to $3: 4$ ) that strongly support gel formation. Weiserová et al. (2011) emphasized that specific interactions also occur between monophosphates and triphosphates that influence the properties of processed cheeses. On the other hand, polyphosphates are thought to inhibit gel formation. Within the conditions of processed cheeses, polyphosphates bind to casein fractions and give them a strong multiple negative charge. More intensively charged casein fractions repel each other, which inhibits the formation of some of the above-mentioned bonds (mainly hydrophobic interactions; Mizuno and Lucey, 2007; Shirashoji et al., 2010; Buňka et al., 2013).

Processes such as the exchange of sodium ions for calcium ions and formation of the final matrix (creaming), and thus the roles of the individual phosphates in these processes, are closely related. According to Mizuno and Lucey (2005a,b) and Shirashoji et al. (2010), higher ion-exchange ability is linked to better casein dispersion in the melt. According to these authors, greater casein dispersion also leads to a more intensive formation of mutual bonds during the creaming process. On the other hand, longer polyphosphates make the negative charge of caseins more intensive and thus weaken the gel (Shirashoji et al., 2010; Buňka et al., 2013). A balance exists between these 2 processes in the melt that seem to be contrary to each other, which is reflected in the final quality of the gel. However, the above-mentioned processes are much more complex because ternary and quaternary mixtures of ES are often used in practice and therefore the mutual interactions between ES must also be taken into consideration (Awad et al., 2002; Weiserová et al., 2011; Buňka et al., 2012).

Over the past few years, several studies (e.g., Awad et al., 2002; Weiserová et al., 2011; Buňka et al., 2012, 2013) have shown the dependence of texture parameters of processed cheeses on the composition of binary and ternary mixtures of phosphate ES (consisting mainly of disodium phosphate, tetrasodium diphosphate, and sodium salt of polyphosphate). In these studies, a specific ratio of disodium phosphate to tetrasodium diphosphate was determined (approximately 1:1 to 3:4), at which hardness of the processed cheeses increased rapidly but cohesiveness and adhesiveness decreased. The influence of this specific ratio decreased with an increasing relative amount of sodium salt of polyphosphate. When the amount of sodium salt of polyphosphate exceeded $60 \%$, the influence of this specific ratio became insignificant. The phenomena were not affected by the maturity stage of the raw material (Dutch-type cheese; maturity stage within the range of 2 to $8 \mathrm{wk}$ ) or the concentration of the ES (2-3\% wt/wt; Kapoor et al., 2007; Weiserová et al., 2011; Buňka et al., 2012, 2013).

However, existing studies are limited to linear-chain polyphosphates with mean length ( $\mathrm{n}$; the number of phosphorus atoms bound in a linear molecule of polyphosphate) of about 20 (Sádlíková et al., 2010; Weiserová et al., 2011; Buňka et al., 2012, 2013). On the other hand, sodium salts of polyphosphate with different mean lengths of chain are often used in practice. Chains of different length could affect the intensity of the exchange of sodium ions for calcium ions and thus casein dispersion (Mizuno and Lucey, 2007; Lu et al., 2008; Sádlíková et al., 2010). On the basis of the available literature, this hypothesis has not yet been proved experimentally. The role of polyphosphates with different chain lengths in mixtures with triphosphates, diphosphates, and monophosphates during the process of casein dispersion has not been described either. A different number of phosphorus atoms in a linear chain could also affect the creaming process; for example, by means of interactions with casein fractions of varying intensity. Moreover, the use of polyphosphates with different chain lengths can also affect the $\mathrm{pH}$ of the product (Lu et al., 2008). Finally, no studies have dealt with the influence of different compositions of ternary mixtures of ES containing triphosphate on the texture parameters of processed cheeses.

The first aim of this study was to compare selected texture parameters (hardness, cohesiveness, and relative adhesiveness) of model processed cheeses made with ternary mixtures of phosphate ES with the addition of sodium salts of polyphosphate with different mean lengths. The second aim was to observe the influence of the replacement of pentasodium triphosphate with tetrasodium diphosphate in ternary mixtures of ES on the textural properties of model processed cheeses. The above-mentioned parameters were observed (1) with nonadjusted $\mathrm{pH}$ of the processed cheeses arising from the interactions of the ES mixtures, and (2) with adjusted $\mathrm{pH}$ values of the samples (target $\mathrm{pH}$ values in the range from 5.60 to 5.80), which correspond to standard $\mathrm{pH}$ values of processed cheese spreads. The third aim was to study the link between the development of selected texture parameters of model processed cheeses related to different composition of ternary mixtures of phosphate ES and the effect of these mixtures on dispersion of casein micelles in the model milk system.

\section{MATERIALS AND METHODS}

\section{Processed Cheese Manufacturing}

Composition of the ingredients (Dutch-type cheese blocks, $\sim 50 \% \mathrm{wt} / \mathrm{wt} \mathrm{DM}$ content; $\sim 30 \% \mathrm{wt} / \mathrm{wt}$ fat in 
DM content, 7 -wk maturity; butter $\sim 82 \%$ wt/wt DM content; $\sim 80 \% \mathrm{wt} / \mathrm{wt}$ fat content; and water) for the production of model processed cheese spreads was designed to reach the target values of DM content and fat in DM content of processed cheeses of 40 and $50 \%$ (wt/ wt), respectively. First, ternary mixtures of disodium phosphate (DSP), tetrasodium diphosphate (TSPP), and 5 sodium salts of polyphosphate $(\mathbf{P x x})$ with different mean length $(\mathrm{n} \approx 5,9,13,20$, and 28 ; designated P05, P09, P13, P20, and P28, respectively) were used as ES, which resulted in 5 ternary mixtures of DSP:TSPP:Pxx (for P05, P09, P13, P20, and P28). Another 5 ternary mixtures (DSP:PSTP:Pxx) were formed by using pentasodium triphosphate (PSTP) instead of TSPP in the mixtures. All 10 ternary mixtures of sodium salts of phosphates (DSP:TSPP/PSTP:Pxx) were applied in percentage proportions with increments of $20 \%$ together with some specific ratios with $50 \%$ of some salts (100:0:0; 80:20:0; 60:40:0; 50:50:0; 40:60:0; 20:80:0; 0:100:0; 80:0:20; 60:20:20; 40:40:20; 20:60:20; $0: 80: 20 ; \quad 60: 0: 40 ; \quad 40: 20: 40 ; \quad 20: 40: 40 ; \quad 0: 60: 40 ; \quad 50: 0: 50$; 30:20:50； 20:30:50； 0:50:50； 40:0:60； 20:20:60； 0:40:60; $20: 0: 80 ; 0: 20: 80 ; 0: 0: 100 ; 26$ variants in total). Each combination was made 3 times for a total of 780 lots ( 26 variants $\times 10$ types of ternary mixtures $\times 3$ productions). The ES were supplied by Fosfa PLC (BřeclavPoštorná, Czech Republic). All ternary mixtures were applied at the total concentration of $3 \%$ (wt/wt) of the ES (the amount calculated based on the total weight of the melt).

Subsequently, model samples with $\mathrm{pH}$ adjusted to reach the optimal range for $\mathrm{pH}$ of the processed cheese spreads were made; the target value was $\mathrm{pH} 5.60$ to 5.80. The $\mathrm{pH}$ values were adjusted by adding $\mathrm{NaOH}$ or $\mathrm{HCl}(1 \mathrm{~mol} / \mathrm{L})$. The model samples were produced the same way as the products without any $\mathrm{pH}$ adjustment. The calculated amount of acid or alkali (the amount based on a calibration model made in the pilot study; unpublished data) was added to the manufacturing equipment at 85 to $86^{\circ} \mathrm{C}$ (approximately 30 to $50 \mathrm{~s}$ before reaching the melting temperature). The addition of water was decreased by the calculated amount of $\mathrm{NaOH}$ or $\mathrm{HCl}$ (to reach a constant DM content and fat in DM content). A total of 780 lots (26 variants $\times 10$ types of ternary mixtures $\times 3$ productions) were made in this way (with $\mathrm{pH}$ adjustment).

The model samples were produced using a Vorwerk Thermomix TM 31-1 blender cooker (Vorwerk \& Co., GmbH, Wuppertal, Germany). The same equipment was also used for the production of processed cheeses in the work of Lee et al. (2004) and Macků et al. (2008). The melting temperature of $90^{\circ} \mathrm{C}$ was kept for $1 \mathrm{~min}$ (the total melting time of 10-12 min). The hot melt was poured into cylindrical polypropylene pots $(52 \mathrm{~mm}$ in diameter; $50 \mathrm{~mm}$ high) and sealed with aluminum lids. Within $2 \mathrm{~h}$ after the production, the samples were cooled to $6 \pm 2^{\circ} \mathrm{C}$, and stored at that temperature until the analyses were started. The products were tested on d 2,9 , and 30 of storage $\left(6 \pm 2^{\circ} \mathrm{C}\right.$; d 1 was the day of the production).

Dry matter content (ISO, 2004) and pH (measured by direct insertion of a spear electrode into the model samples; pHSpear, Eutech Instruments, Oakton, Malaysia) were determined in the model samples. Each variant of the sample was measured 9 times.

\section{Texture Analysis}

Textural properties of the model samples were assessed by 2 sequential penetration events by means of TA.XT Plus texture analyzer (Stable Micro Systems Ltd., Godalming, UK). A cylindrical probe $20 \mathrm{~mm}$ in diameter was used (strain of deformation 25\%, probe speed $2 \mathrm{~mm} / \mathrm{s}$ ). According to the force-deformation curve describing the dependence of the force needed $(\mathrm{N})$ on time (s), the following texture parameters were determined: hardness, cohesiveness, and relative adhesiveness (Cunha and Viotto, 2010; Weiserová et al., 2011; Bayarri et al., 2012; Cunha et al., 2013). Each parameter was measured 9 times.

\section{Preparation of the Model Milk Samples and Measurement of Turbidity}

Evaluation of the intensity of casein dispersion is based on the method of measuring optical density ("turbidity") developed by Kaliappan and Lucey (2011). It is assumed that the lower the optical density, the greater the casein dispersion that has been achieved. Skim milk powder (Moravia Lacto PLC, Jihlava, Czech Republic) stirred in deionized water; an amount corresponding to $5 \%(\mathrm{wt} / \mathrm{vol}$ ) was used as the model milk system. After careful stirring, dissolving $(\sim 1 \mathrm{~h}$ of stirring at a laboratory temperature $22 \pm 1^{\circ} \mathrm{C}$ ), and addition of sodium azide $(0.2 \% \mathrm{wt} / \mathrm{vol})$, the $\mathrm{pH}$ of the system was adjusted to reach $5.80 \pm 0.01(\mathrm{HCl}$ at 1 and $0.1 \mathrm{~mol} / \mathrm{L}$ was added for fine adjustment of $\mathrm{pH}$ ) and kept overnight $(\sim 18 \mathrm{~h})$ at $22 \pm 1^{\circ} \mathrm{C}$ to stabilize the environment. Subsequently, 10 ternary mixtures of phosphate ES (DSP:TSPP/PSTP:Pxx) were applied in percentage proportions with increments of $20 \%$ and some specific ratios with $50 \%$ of some salts (the same ratios as during the production of processed cheeses; 26 variants in total). Each combination was produced 3 times for 780 model milk systems in total ( 26 variants $\times 10$ types of ternary mixtures $\times 3$ productions). The ternary mixtures of ES were added at a total concentration of $0.3 \%$ (wt/vol). After the addition of ES, the mixtures were 
stirred for $10 \mathrm{~min}$ and the $\mathrm{pH}$ was adjusted to reach the value of $5.80 \pm 0.01(\mathrm{NaOH}$ or $\mathrm{HCl}$ at 1 and 0.1 $\mathrm{mol} / \mathrm{L}$ were used for fine adjustments). The mixture was stirred at room temperature $\left(22 \pm 1^{\circ} \mathrm{C}\right)$ for another 50 min. Subsequently, the optical density was measured at $\lambda=700 \mathrm{~nm}$ (UV-VIS Spectrophotometer, UV Mini 1240, Shimadzu, Duisburg, Germany). The results were expressed with respect to the optical density of the milk system without the addition of $\mathrm{ES}$, the $\mathrm{pH}$ of which was adjusted to reach $5.80 \pm 0.01$ (100\%; after $\sim 18 \mathrm{~h})$. Each variant (including the control sample) was measured 9 times.

For comparison of $\mathrm{pH}$ of individual phosphate salts used, model samples consisting of deionized water or dairy model system (skim milk powder in deionized water $5 \% \mathrm{wt} / \mathrm{vol}$ ) with tested individual phosphate salts (1\% wt/vol) were also produced.

\section{Statistical Analysis}

The results of chemical and texture analysis and optical density measurements were subjected to nonparametrical ANOVA by Kruskal-Wallis and Wilcoxon tests (Unistat 5.5 software; Unistat, London, UK). The significance level used in the tests was 0.05.

\section{RESULTS}

\section{Basic Chemical Analysis}

Dry matter content, which was determined in all variants of the model samples tested, ranged from 40.56 to $41.22 \%$ (wt/wt). This range is acceptable in showing consistency of DM content in the individual variants of processed cheeses. Dry matter content is an important parameter that influences the textural properties of processed cheeses, and maintaining a consistent DM content is important for ensuring the comparability of the individual samples (Lee et al., 2004).
The $\mathrm{pH}$ value of processed cheeses is controlled by the ingredients used for their production and by the ES, the composition of which plays a key role in affecting this parameter. Table 1 shows $\mathrm{pH}$ values of the model solutions of the individual ES in water and in milk systems $(5.0 \% \mathrm{wt} / \mathrm{vol}$ of skim milk powder in deionized water). The $\mathrm{pH}$ of the model solutions decreased significantly $(P<0.05)$ with an increasing number of phosphorus atoms in the phosphate molecule. The range of $\mathrm{pH}$ values in the samples with deionized water (4.21-10.09) was wider compared with that in the milk system (6.22-8.65; comparing the concentration of $1.0 \% \mathrm{wt} / \mathrm{vol}$ ). This difference could be explained by the buffer capacity of the milk system (Mizuno and Lucey, 2005a; Kaliappan and Lucey, 2011).

The $\mathrm{pH}$ values of the processed cheeses with the addition of the individual phosphate ES are shown in Table 1 (d 2 after production, stored at $6^{\circ} \mathrm{C}$ ). The highest $\mathrm{pH}$ values were reached when using DSP, TSPP, or PSTP separately $(P<0.05)$ compared with the processed cheeses with the addition of other ES. A slightly lower $\mathrm{pH}$ value compared with the previous products (5.95 $\pm 0.02 ; P<0.05)$ was observed in the samples made with $\mathrm{P} 05$. The $\mathrm{pH}$ values of the samples with addition of P09, P13, P20, or P28 ES did not show a significant difference $(P \geq 0.05)$ and ranged from 5.34 to 5.45 . The development of $\mathrm{pH}$ values of the processed cheeses with the ES applied separately was in accord with the trend of changes in $\mathrm{pH}$ of the model solutions (Table 1).

Figure 1 illustrates the dependence of $\mathrm{pH}$ of the model samples of processed cheeses (after $2 \mathrm{~d}$ of storage at $6^{\circ} \mathrm{C}$ ) without any $\mathrm{pH}$ adjustment on the composition of ternary mixtures of ES. It shows the $\mathrm{pH}$ values of products made using ternary mixtures containing DSP:TSPP:P05 or DSP:TSPP:P28. When using only DSP with TSPP (without polyphosphates), the $\mathrm{pH}$ of the processed cheeses was high $(\mathrm{pH}>6.40 ; P<0.05)$. With an increasing proportion of polyphosphates,

Table 1. The $\mathrm{pH}$ values of $1.0 \%$ (wt/vol) of the individual emulsifying salts (ES) in deionized water, of the model milk system (5.0\% wt/vol of skim milk powder in deionized water) with $0.3 \%$ (wt/vol) or $1.0 \%$ (wt/vol) of the individual ES, and of the model processed cheese with $3.0 \%$ (wt/wt) of the individual ES (mean $\pm \mathrm{SD} ; \mathrm{n}=9$ )

\begin{tabular}{|c|c|c|c|c|c|}
\hline Emulsifying salt & Code & $\begin{array}{l}1.0 \% \mathrm{ES} \text { in } \\
\text { deionized water }\end{array}$ & $\begin{array}{l}0.3 \% \mathrm{ES} \text { in } \\
\text { model milk system }\end{array}$ & $\begin{array}{l}1.0 \% \mathrm{ES} \text { in } \\
\text { model milk system }\end{array}$ & $\begin{array}{l}\text { Processed cheese } \\
\text { with } 3.0 \% \mathrm{ES}^{1}\end{array}$ \\
\hline Disodium phosphate & DSP & $9.43 \pm 0.01$ & $6.56 \pm 0.01$ & $7.20 \pm 0.01$ & $6.45 \pm 0.02$ \\
\hline Tetrasodium diphosphate & TSPP & $10.06 \pm 0.02$ & $6.68 \pm 0.01$ & $8.62 \pm 0.01$ & $6.63 \pm 0.03$ \\
\hline Pentasodium triphosphate & PSTP & $9.93 \pm 0.02$ & $6.49 \pm 0.03$ & $7.89 \pm 0.02$ & $6.41 \pm 0.03$ \\
\hline \multicolumn{6}{|l|}{ Sodium salt of polyphosphate ${ }^{2}$} \\
\hline$(\mathrm{n} \approx 5)$ & $\mathrm{P} 5$ & $8.46 \pm 0.02$ & $6.30 \pm 0.01$ & $6.98 \pm 0.01$ & $5.95 \pm 0.02$ \\
\hline$(\mathrm{n} \approx 9)$ & P9 & $7.14 \pm 0.01$ & $6.17 \pm 0.01$ & $6.46 \pm 0.01$ & $5.44 \pm 0.02$ \\
\hline$(\mathrm{n} \approx 13)$ & $\mathrm{P} 13$ & $6.82 \pm 0.01$ & $6.15 \pm 0.01$ & $6.45 \pm 0.01$ & $5.38 \pm 0.03$ \\
\hline$(\mathrm{n} \approx 20)$ & P20 & $5.93 \pm 0.01$ & $6.13 \pm 0.02$ & $6.26 \pm 0.01$ & $5.36 \pm 0.01$ \\
\hline$(\mathrm{n} \approx 28)$ & P28 & $4.27 \pm 0.02$ & $6.14 \pm 0.01$ & $6.25 \pm 0.01$ & $5.35 \pm 0.02$ \\
\hline
\end{tabular}

${ }^{1} \mathrm{pH}$ values after $2 \mathrm{~d}$ of storage at $6^{\circ} \mathrm{C}$.

${ }^{2}$ Where $\mathrm{n}$ indicates the length of the polyphosphate. 


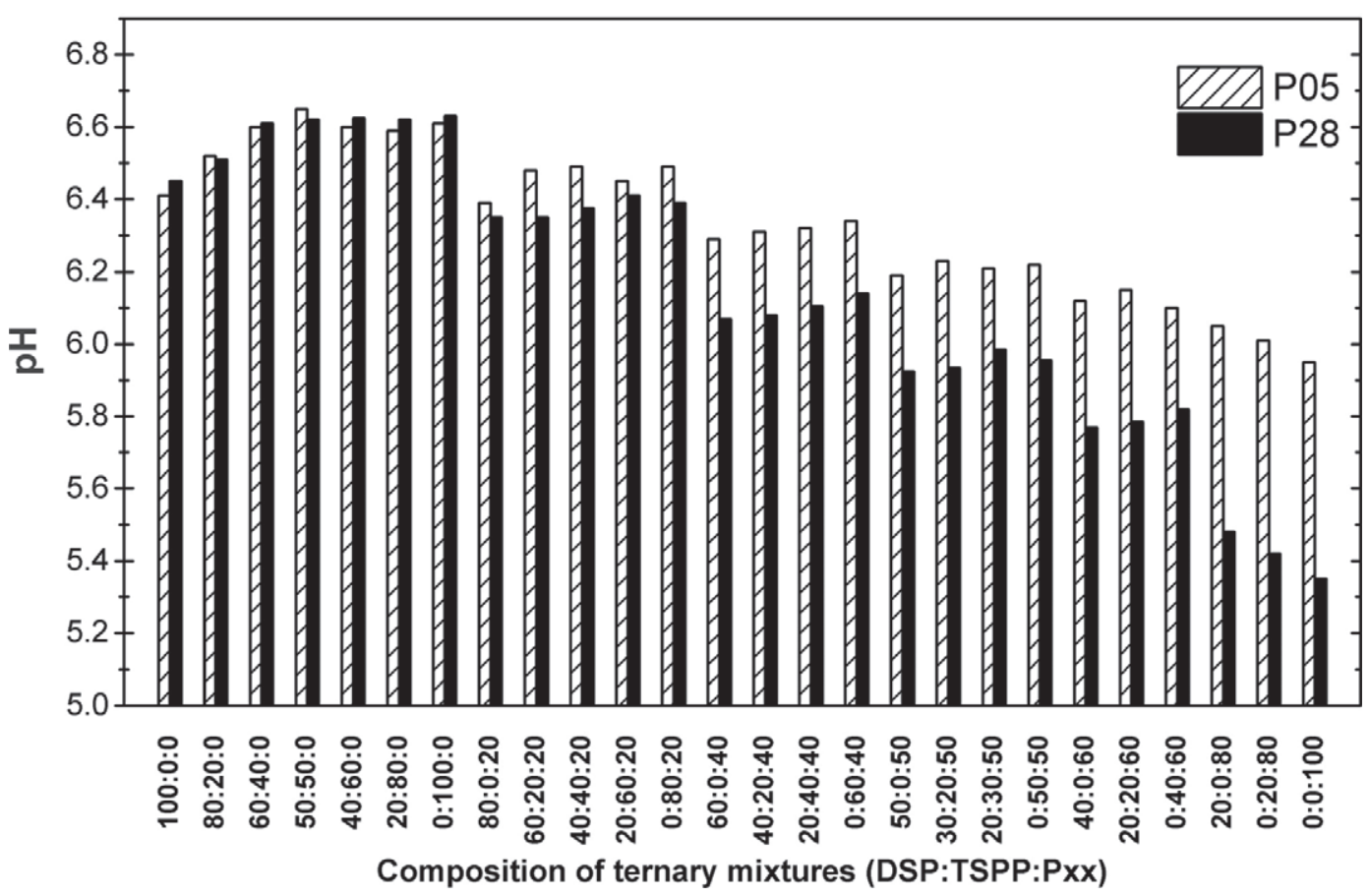

Figure 1. The dependence of $\mathrm{pH}$ values of the model samples (stored for $2 \mathrm{~d}$ at $6^{\circ} \mathrm{C}$ ) on the relative amount (x-axis; \%) of disodium phosphate (DSP), tetrasodium diphosphate (TSPP), and sodium salts of polyphosphate (P05, sodium salts of polyphosphate with medium length, $\mathrm{n} \approx 5 ; \mathrm{P} 28=$ sodium salts of polyphosphate with medium length, $\mathrm{n} \approx 28$ ) in a ternary mixture of emulsifying salts. The results are expressed as means $(\mathrm{n}=9)$.

the $\mathrm{pH}$ decreased gradually $(P<0.05)$. The slowest decrease in $\mathrm{pH}$ of the processed cheeses (with an increasing proportion of polyphosphate) was observed in samples with the ternary mixtures containing P05. On the other hand, $\mathrm{pH}$ values of the samples containing P28 decreased fastest $(P<0.05$; Figure 1$)$. The development of $\mathrm{pH}$ values of processed cheeses with other ternary mixtures with TSPP (DSP:TSPP:P09, DSP:TSPP:P13, and DSP:TSPP:P20; data not shown) was analogous and values ranged within the interval defined by $\mathrm{pH}$ values of DSP:TSPP:P05 and DSP:TSPP:P28. The replacement of TSPP with PSTP did not lead to any significant differences in $\mathrm{pH}$ values of the model samples $(P \geq 0.05$; data not shown $)$ when comparing corresponding samples (e.g., processed cheeses made using ternary mixtures of DSP:TSPP:P09 and DSP:PSTP:P09 at a ratio of 40:20:40 stored for 9 d at $\left.6^{\circ} \mathrm{C}\right)$.

The real $\mathrm{pH}$ values in the model processed cheeses with $\mathrm{pH}$ adjustment (to reach the intended target $\mathrm{pH}$ of 5.60-5.80) ranged from 5.65 to 5.81 (data not shown). With respect to production from cheese and butter, the interval achieved can be considered acceptable. During a 30-d storage period at $6^{\circ} \mathrm{C}$, a slight decrease in $\mathrm{pH}$ of the model samples occurred. In most samples, the decrease was between 0.1 and $0.2 \mathrm{pH}$ units $(P<0.05)$.

\section{Effect of the Composition of Phosphate Ternary Mixtures on Texture Parameters}

Figure $2 \mathrm{~A}-\mathrm{C}$ shows the values of hardness of the model samples for the ternary mixtures of ES of DSP:TSPP:P05 after 2 (panel A), 9 (panel B), and 30 (panel C) d of storage at $6^{\circ} \mathrm{C}$. A content of P05 $\leq 60 \%$ in the ternary mixtures of ES led to a rapid increase in hardness of the products at a specific ratio of DSP to TSPP of approximately 1:1 to 3:4 (Figure 2 ). Any deviation of the ratio of DSP to TSPP (with a constant content of $\mathrm{P} 05$ ) resulted in a rapid decrease in hardness. The influence of the specific ratio of DSP to TSPP decreased with an increasing proportion of P05 in the ternary mixtures $(P<0.05)$. With an increasing proportion of $\mathrm{P} 05>60 \%$, the ratio of DSP to TSPP did not have a significant influence on hardness of the samples $(P \geq 0.05$; comparing the model processed cheeses with a constant storage period). This general development concerning the dependence of hardness of the model processed cheeses on the composition of ternary mixtures of ES was observed regardless of the storage period of the model samples (Figure 2). With an extending storage period, an increase in the absolute values of hardness of the processed cheeses was observed $(P<0.05$; comparing the samples made using a constant ratio of DSP:TSPP:P05). 


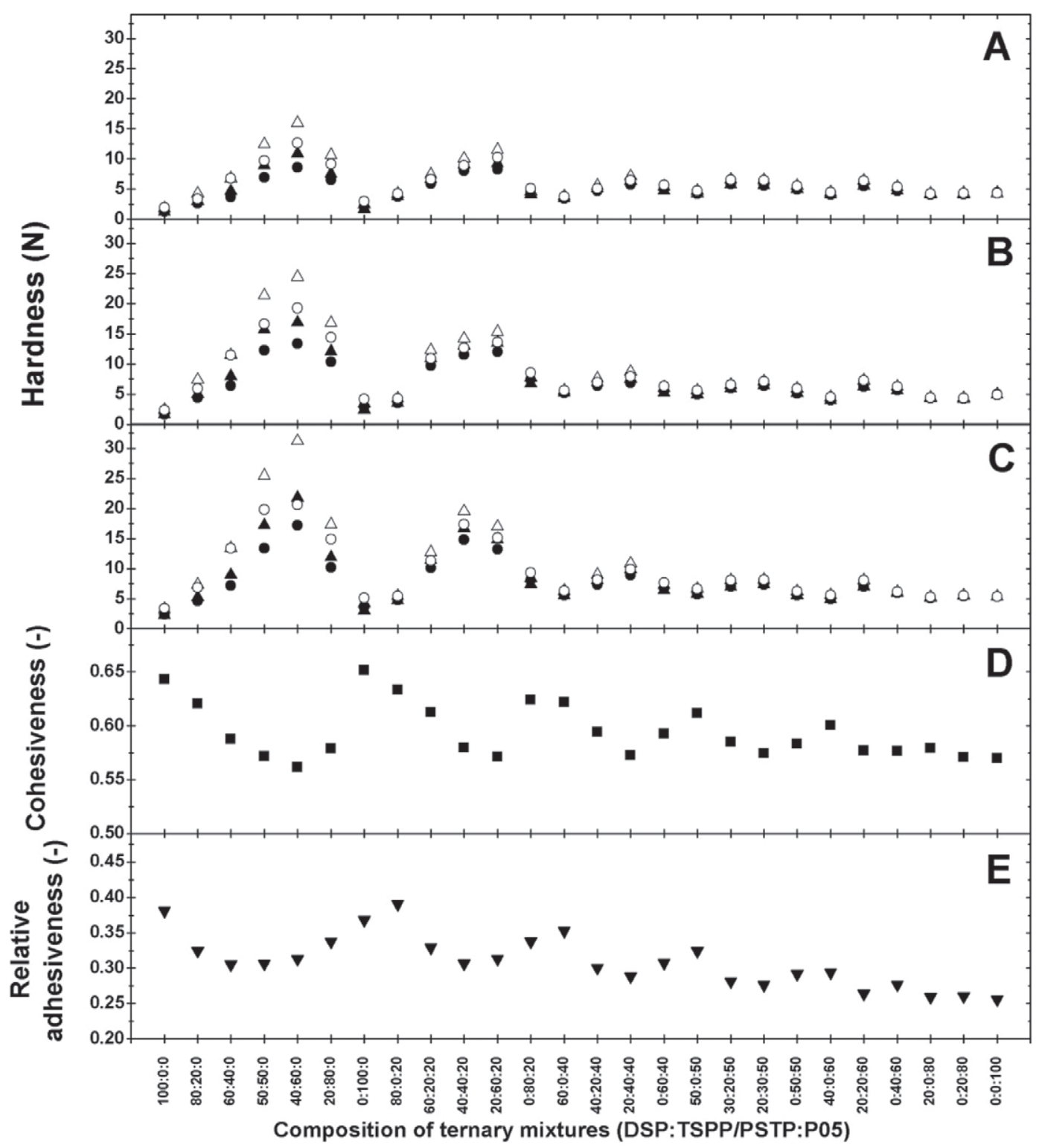

Figure 2. The dependence of processed cheese hardness (panels A to C), cohesiveness (unitless; panel D) and relative adhesiveness (unitless; panel E) on the relative amount (x-axis; \%) of disodium phosphate (DSP), tetrasodium diphosphate (TSPP), or pentasodium triphosphate (PSTP), and sodium salt of polyphosphate (P05, sodium salt of polyphosphate with medium length, $\mathrm{n} \approx 5$ ) in a ternary mixture of emulsifying salts during $30 \mathrm{~d}$ of storage at $6^{\circ} \mathrm{C}(\mathrm{A}: \mathrm{d} 2$; B: d 9; C: $\mathrm{d} 30)$. The solid symbols (A to C) represent the samples without adjustment of pH values, and the open symbols represent the samples whose $\mathrm{pH}$ values were adjusted to the optimal range of 5.65 to 5.81 . The results of hardness in processed cheese containing TSPP and PSTP are depicted using triangles $(\boldsymbol{\Lambda}, \Delta)$ and circles $(\bullet, \bigcirc)$, respectively, in panels A to C. The results of cohesiveness $(\mathrm{D} ; \boldsymbol{\nabla})$ and relative adhesiveness $(\mathrm{E} ; \mathbf{\nabla})$ are for the ternary mixtures containing TSPP on d 2 of storage.

The results of the dependence of cohesiveness and relative adhesiveness of the processed cheeses on the composition of ternary mixtures of DSP:TSPP:P05 for d 2 of storage at $6^{\circ} \mathrm{C}$ are illustrated in Figure $2 \mathrm{D}$ and E. With a constant content of $\mathrm{P} 05 \leq 60 \%$, a rapid decrease in cohesiveness of the processed cheeses was observed at a ratio of DSP to TSPP of 1:1 to 1:2. Under the same conditions (a constant content of P05 $\leq 60 \%$ ), a rapid decrease in relative adhesiveness of the samples was observed at a ratio of DSP to TSPP from 1:1 to 3:4. Outside this specific interval for the ratio of DSP to TSPP, both cohesiveness and relative adhesiveness of the samples increased significantly (compared with the samples with a constant content of P05). With an increasing proportion of $\mathrm{P} 05$ in the ternary mixtures of ES (up to 60\%; Figure 2D and E), the influence of the specific ratio of DSP to TSPP on cohesiveness and relative adhesiveness of the samples decreased. With 
a proportion of $\mathrm{P} 05>60 \%$, only a gradual decrease in cohesiveness and relative adhesiveness was observed, regardless of the ratio of the other $2 \mathrm{ES}$ (Figure 2D and E). This general trend corresponded to the description of dependence of cohesiveness and relative adhesiveness of the samples on the proportion of DSP, TSPP, and P05 in the ternary mixtures of ES, regardless of the storage period. After a 30-d storage period, a slight increase in the values of cohesiveness and a decrease in the values of relative adhesiveness occurred (comparing model processed cheeses made with a constant ratio of DSP:TSPP:P05 in the ternary mixture of ES; data not shown). However, most of these changes (depending on the storage period) were not significant $(P \geq 0.05)$.

The above-mentioned dependence of the texture parameters of processed cheeses on the composition of ternary mixtures was presented on one type of ternary mixture (DSP:TSPP:P05) in the samples without $\mathrm{pH}$ adjustment. Different numbers of phosphorus atoms linearly bound in the polyphosphates added to the ternary mixtures with DSP and TSPP did not result in a significant change in the above-mentioned specific ratios (Figure 3). During application of all the polyphosphates tested (P05, P09, P13, P20, and P28), the interval for the value of the specific ratio of DSP:TSPP (which rapidly increased hardness and significantly decreased cohesiveness and relative adhesiveness of the processed cheeses) remained unchanged $(P \geq 0.05)$. However, the absolute values of textural parameters were affected, especially those showing hardness of the samples (Figure 3). In the case of P05 and P09, the absolute values of hardness of the model cheeses were slightly higher with the application of ternary mixtures with 20 and $40 \%$ polyphosphate content compared with the products with the application of P20 and P28 polyphosphates $(P<0.05$; Figure 3$)$. The same trend for an increase in hardness of the model samples was observed in the ternary mixtures with 50\% P05 and P09 (compared with the application of P20 and P28 polyphosphates) but these changes were not significant $(P \geq 0.05$; Figure 3$)$.

With the application of polyphosphate reaching $\geq 60 \%$, hardness of the processed cheeses decreased slowly as the number of phosphate units decreased (Figure 3). Significant differences were observed mainly between the samples with P05 and P09 compared with P20 and P28 $(P<0.05)$. Significant differences in hardness between the samples with P20 and P28 polyphosphates were not observed $(P \geq 0.05)$; the same was true for samples containing P05 and P09 $(P \geq$ 0.05). The absolute values of hardness of the processes cheeses with the application of $\mathrm{P} 13$ were close to that of samples containing P20 or P28 (Figure 3).
The application of PSTP in the ternary mixtures did not result in any changes in the general trends of dependence of the processed cheeses hardness on the composition of ternary mixtures of phosphates (compared with the application of TSPP; Figures 2 and 3). The replacement of TSPP with PSTP affected only the absolute values of hardness in some model samples. Significantly lower $(P<0.05$; Figures 2 and 3$)$ absolute values of hardness of the processed cheeses (with the exception of DSP and PSTP used on their own) were observed with a zero content of polyphosphate compared with the products containing TSPP. A similar conclusion concerning lower hardness of the model samples was reached for $20 \%$ and $40 \%$ polyphosphate content in the ternary mixtures $(P<0.05$; compared with the same ternary mixtures containing TSPP; Figures 2 and 3). Changes in hardness of the processed cheeses containing $\geq 50 \%$ polyphosphate were not statistically significant $(P \geq 0.05)$, regardless of the storage period. A longer storage period led to an increase in the values of hardness of the processed cheeses $(P<0.05)$ regardless of the ternary mixture used.

The values of cohesiveness of model samples ranged from 0.49 to 0.69 . The values of relative adhesiveness of the individual samples of processed cheeses ranged from 0.20 to 0.41 . Extending the length of the polyphosphate chain resulted in no clear trend in the changes of cohesiveness or relative adhesiveness of the model processed cheeses.

Adjusting the $\mathrm{pH}$ of the processed cheeses (to reach the optimal range of 5.65-5.81) significantly influenced $(P<0.05)$ the absolute values of hardness (Figures 2 and 3), cohesiveness, and relative adhesiveness (data not shown) of the samples (compared with the products without any $\mathrm{pH}$ adjustment). In products where $\mathrm{pH}$ was increased (by means of $\mathrm{NaOH}$ ), the hardness and cohesiveness decreased, whereas relative adhesiveness increased slightly. When the $\mathrm{pH}$ of the processed cheeses was decreased (by means of $\mathrm{HCl}$ ), hardness and cohesiveness of the samples increased and relative adhesiveness decreased. The greater the shift in $\mathrm{pH}$, the more significant changes were observed (Figures 2 and 3). Adjusting the $\mathrm{pH}$ did not have a significant effect on the general trends of changes resulting from the application of sodium salts of polyphosphates with different lengths of chain (P5, P9, P13, P20, and P28) or from the replacement of TSPP with PSTP (Figures 2 and 3$)$.

\section{Results of the Optical Density Measurement of Milk Systems}

The intensity of casein dispersion in $5 \%$ (wt/vol) milk system was evaluated by measuring the optical density 


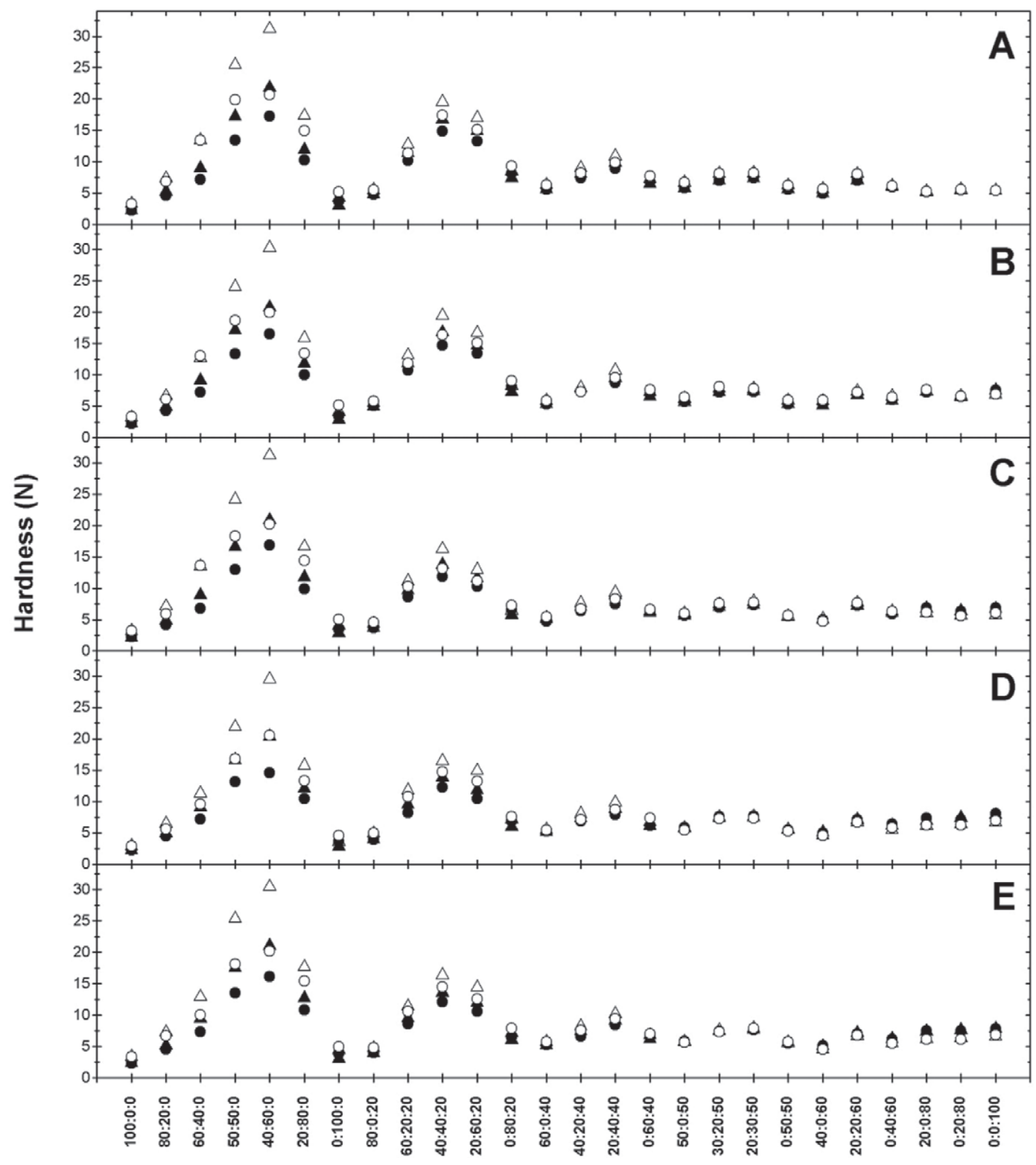

Composition of ternary mixtures (DSP:TSPP/PSTP:Pxx)

Figure 3. The dependence of processed cheese hardness on the relative amount (x-axis; \%) of disodium phosphate (DSP), tetrasodium diphosphate (TSPP), or pentasodium triphosphate (PSTP) and sodium salt of polyphosphate (with different chain lengths): P05 (n $\approx 5$, panel A), P09 $(\mathrm{n} \approx 9$, panel B), P13 $(\mathrm{n} \approx 13$, panel C), P20 $(\mathrm{n} \approx 20$, panel $\mathrm{D})$, and P28 $(\mathrm{n} \approx 28$, panel E) in a ternary mixture of emulsifying salts after $30 \mathrm{~d}$ of storage at $6^{\circ} \mathrm{C}$. The solid symbols (A to C) represent the samples without adjustment of $\mathrm{pH}$ values, and the open symbols represent the samples whose $\mathrm{pH}$ values were adjusted to the optimal range of 5.65 to 5.81 . The results of processed cheese hardness containing TSPP and PSTP are depicted using triangles $(\boldsymbol{\Lambda}, \Delta)$ and circles $(\bullet, \bigcirc)$, respectively, in panels A to C.

at $\lambda=700 \mathrm{~nm}$. The principle of this method is based on the assumption that the lower the value of optical density in the milk system, the more the casein is dispersed (Kaliappan and Lucey, 2011). The results of the optical density measurement of milk system containing the ternary mixtures of DSP, TSPP, and Pxx are shown in Figure 4 (the results were expressed as percentage with respect to the control sample, milk system without any phosphate addition). The addition of ternary mixtures of phosphates was set at $0.3 \%$ (wt/vol), which corresponds to the ratio of protein:phosphate in processed cheeses (Guinee et al., 2004).

When applying the phosphates individually, the intensity of casein dispersion increased with an increasing number of phosphorus atoms linearly bound in the phosphate molecule $(P<0.05$; Figure 4 ; for PSTP used 

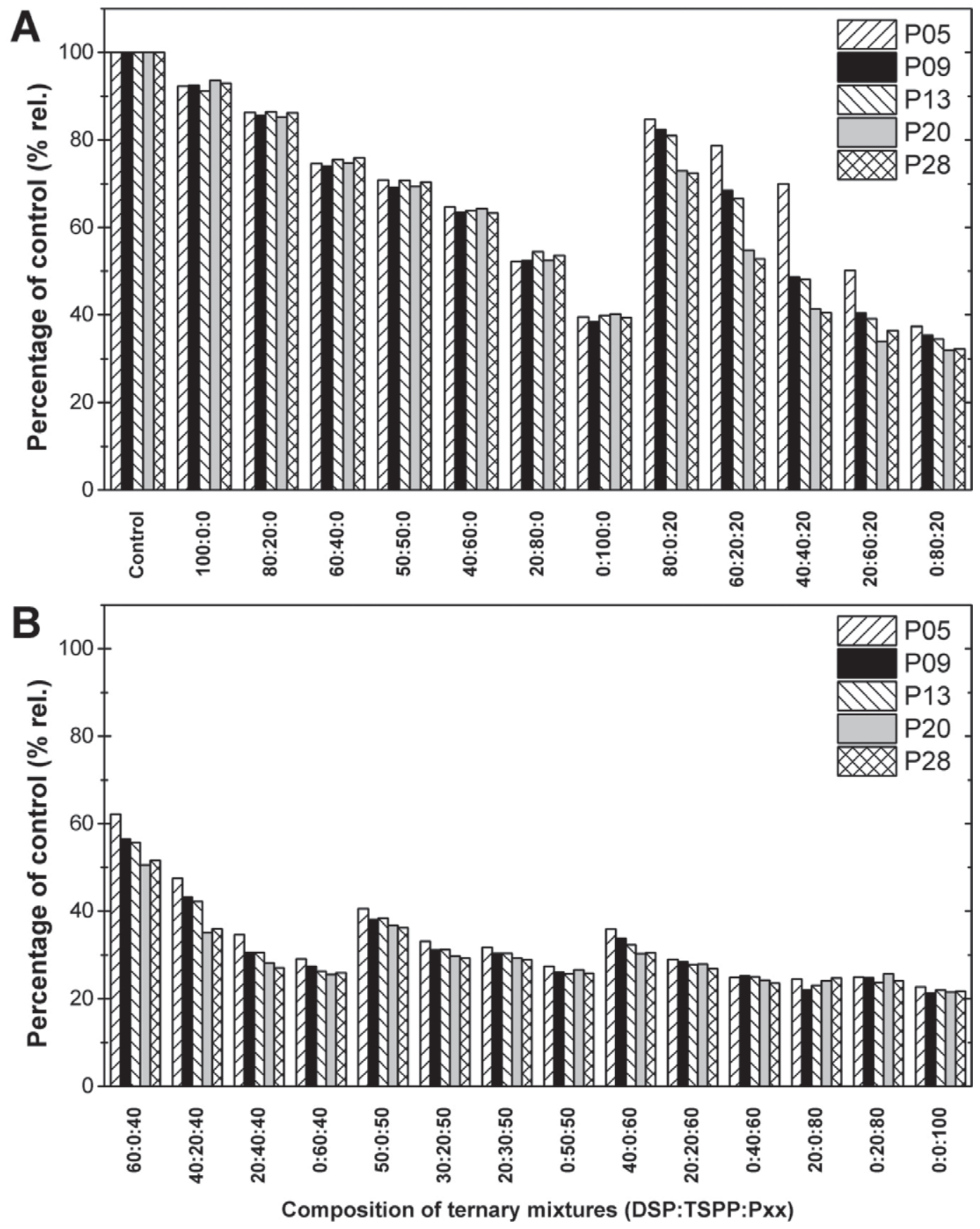

Figure 4. The dependence of percentage of absorbance of the model milk systems (\% rel.; in relation to the model milk systems without phosphate addition $=100 \%$ ) on the relative amount (x-axis; \%) of disodium phosphate (DSP), tetrasodium diphosphate (TSPP), and sodium salt of polyphosphate (with different chain lengths): P05 $(\mathrm{n} \approx 5), \mathrm{P} 09(\mathrm{n} \approx 9), \mathrm{P} 13(\mathrm{n} \approx 13), \mathrm{P} 20(\mathrm{n} \approx 20)$, and P28 ( $\approx 28)$ in a ternary mixture of emulsifying salts. The results are expressed as means $(\mathrm{n}=9)$.

individually, the values ranged from 31 to $33 \%$ with respect to the value of optical density in the control sample), which corresponds to several published studies (Mizuno and Lucey, 2005a; Kaliappan and Lucey, 2011). In the ternary mixtures of DSP, TSPP, and Pxx, the intensity of casein dispersion increased with an in- creasing proportion of longer-chain phosphates (Figure 4). Significant differences between casein dispersion were observed mainly in the milk systems containing 20 and $40 \%$ of the individual $\operatorname{Pxx}(P<0.05$; Figure 4). No significant differences $(P \geq 0.05)$ between the milk systems containing different $\mathrm{Pxx}$ were observed 
with 80 and $100 \%$ Pxx content. In the ternary mixtures containing DSP, PSTP, and Pxx, the general trends determined were similar to those of the ternary mixtures with TSPP (data not shown).

\section{DISCUSSION}

During the production of processed cheeses, phosphate ES play an important role in dispersion of the caseins present and subsequent formation of the final matrix of the processed cheeses; that is, the creaming process. Emulsifying salts also play a part in $\mathrm{pH}$ adjustment and stabilization (Marchesseau et al., 1997; Kawasaki, 2008). On the basis of our results, the pH of the processed cheeses decreases when the length of the linear phosphate chain is extended. This might be explained by the release of hydrogen cations (which are more numerous in long phosphates compared with shorter phosphates) into the melt, which decreases the $\mathrm{pH}$. Therefore, the application of longer phosphates requires an adjustment of the $\mathrm{pH}$ of the processed cheeses by means of other ES to reach the optimal range for the given type of product.

The intensity of casein dispersion in the melt depends mainly on the type and concentration of the ES (Carić and Kaláb, 1997; Brickley et al., 2008; Dimitreli and Thomareis, 2009). From our results concerning the optical density measurement of milk systems with ternary mixtures of phosphates, more intensive casein dispersion is reached (1) with the application of a greater amount of polyphosphates (in ternary mixture); and (2) when using polyphosphates with a longer chain. This could be explained by the fact that the longer chain length of sodium salts of phosphates affects the intensity of ion exchange (of sodium ions for calcium ions). The addition of ES leads to casein dispersion, the intensity of which increases with the intensity of ion exchange (Mizuno and Lucey, 2007; Dimitreli and Thomareis, 2009). According to Dimitreli and Thomareis (2009), Shirashoji et al. (2010), and Cunha et al. (2013), casein dispersion is closely related to matrix formation of the final processed cheeses. More intensive casein dispersion enables these proteins to develop their emulsifying and hydration abilities and to stabilize the fat and water present in the mixture. Increasing intensity of protein hydration and fat emulsification leads to a higher intensity of interactions in the melt and thus a higher intensity of casein crosslinking. A greater number of cross linkages that are in the matrix of the product will result in a harder processed cheese (Mizuno and Lucey, 2005a; Shirashoji et al., 2010; Bayarri et al., 2012).

The above-mentioned processes can explain the phenomenon that was also observed in our study: the application of long-chain phosphates used individually resulted in greater hardness of the processed cheese $(P<0.05$; Figures 2 and 3$)$. Hardness increased with the application of phosphate ES used individually in the following order: DSP $<$ TSPP $<$ PSTP $<$ P05 $<\mathrm{P} 09 \approx \mathrm{P} 13<\mathrm{P} 20 \approx \mathrm{P} 28$. Similar trends for DSP, TSPP, PSTP, and P20 were published by Weiserová et al. (2011) and Buňka et al. (2012, 2013).

However, casein dispersion processes alone do not sufficiently explain the specific ratio of DSP:TSPP or DSP:PSTP $(\sim 1: 1-3: 4)$ that led to a rapid increase in hardness of the processed cheeses observed in our study. The influence of this specific ratio on texture parameters of the processed cheeses declined as the amount of polyphosphates increased (regardless of their chain length). With the relative amount of polyphosphates reaching $\geq 60 \%$, the influence of the specific ratio on hardness of the processed cheeses became insignificant, in agreement with published studies (Buňka et al., $2012,2013)$. The justification for the existence of the specific ratios of DSP:TSPP or DSP:PSTP ( 1:1-3:4) was sought mainly in the ability of diphosphates and triphosphates to enhance gel formation of milk proteins. In all probability, another important aspect is the ability of monophosphates to permeate into cross-linked caseins and strongly bind water (Mizuno and Lucey, 2007; Shirashoji et al., 2010; Buňka et al., 2012). Kaliappan and Lucey (2011) observed a strong ability of the mixture of mono- and diphosphates to enhance gel formation in model milk systems, which was explained by the fact that monophosphates enhance the formation of bridges between diphosphate complexes with calcium ions and caseins. Mizuno and Lucey (2007) state that an optimal concentration of diphosphates exists for effective gel formation. Excessive or insufficient concentrations of diphosphates can lead to the formation of very weak gels.

The link between decreasing hardness of the processed cheeses with the ratio of DSP:TSPP or DSP:PSTP from 1:1 to $3: 4$ and an increasing concentration of polyphosphates can be found mainly in the ability of polyphosphates to give caseins multiple negative charges, which probably leads to a lower intensity of hydrophobic interactions of the dispersed caseins and thus decreased hardness of the final matrix (Mizuno and Lucey, 2007; Shirashoji et al., 2010; Buňka et al., 2012, 2013). However, confirmation of the abovementioned hypotheses requires several further studies, which should focus mainly on the process of forming a 3-dimensional matrix of the processed cheeses.

Our results revealed that the usage of polyphosphates with different mean length of the linear chain ( 5 to 28 monomers) affects only the absolute values of the texture parameters measured, not the general trends of dependence of the texture parameters on the composi- 
tion of ternary mixtures of ES such as monophosphate: diphosphate:polyphosphate described in Buňka et al. (2012, 2013). The values of the specific ratios of DSP:TSPP or DSP:PSTP leading to a rapid increase in hardness and a decrease in cohesiveness and relative adhesiveness remained practically unchanged, regardless of the length of the polyphosphate used. However, the type of polyphosphate used affected the absolute values of hardness in the processed cheeses, especially with the relative content of the polyphosphate in ternary mixtures reaching 20 to $50 \%$. A decrease in the number of monomers linearly bound in the polyphosphate resulted in an increase in the absolute values of hardness in the processed cheeses with the polyphosphate content of 20 to $50 \%$ within the ternary mixture. The explanation of this phenomenon is not obvious. It might be based on the ability of polyphosphates to give caseins multiple negative charges, which might increase with the length of the linear polyphosphate (Shirashoji et al., 2010; Weiserová et al., 2011; Buňka et al., 2012, 2013). Shorter polyphosphates (i.e., P05 and P09) probably cause a lower intensity of the negative charge on caseins, which can lead to a higher intensity of hydrophobic interactions of the dispersed caseins and thus lower hardness of the final matrix (Shirashoji et al., 2010; Buňka et al., 2013). With a higher relative content of polyphosphates $(>50 \%)$ in the ternary mixtures, the influences of the individual polyphosphates on casein dispersion seem to be predominant, as described above.

Pentasodium triphosphate is thought to enhance gel formation of caseins to a lesser extent than TSPP (Weiserová et al., 2011; Buňka et al., 2013), which could explain the lower values of hardness in the processed cheeses produced by means of ternary mixtures of DSP:PSTP:Pxx with Pxx content of 0 to $50 \%$ compared with the products made by means of ternary mixtures of DSP:TSPP:Pxx.

The adjustment of $\mathrm{pH}$ values to reach the optimal range (5.65-5.81 in our experiment) did not lead to a change in the general trend concerning the dependence of texture parameters on the composition of ternary mixtures of ES such as DSP:TSPP:Pxx or DSP:PSTP:Pxx. Only the absolute values of texture parameters of the samples were affected. An increase in $\mathrm{pH}$ led to a decrease in hardness of the processed cheeses and vice versa. The explanation could lie in the changed intensity of the negative charge on caseins as a result of the fluctuation in $\mathrm{pH}$ values. Increasing $\mathrm{pH}$ leads to a higher intensity of the negative charge on the dispersed caseins, the repulsion of which is stronger and thus the intensity of hydrophobic interactions in the system decreases. These processes result in lower hardness of the final matrix (Marchesseau et al., 1997; Lee and Klostermeyer, 2001).
During a 30-d storage period of the processed cheeses (at $6^{\circ} \mathrm{C}$ ), a slight increase in hardness of the processed cheeses was observed, regardless of the composition of the ternary mixtures of ES applied or $\mathrm{pH}$ adjustment of the melt during production. A more significant change in the texture parameters was observed during the first 9 d. The change in texture parameters between $d 9$ and 30 of storage was much less significant compared with the change between d 2 and 9 of storage, which corresponds to several published studies (Carić and Kaláb, 1997; Weiserová et al., 2011; Buňka et al., 2012, 2013). The change in texture parameters of processed cheeses during their storage period can be explained by several factors: (1) a slight decrease in $\mathrm{pH}$ values of the processed cheeses (also observed in our study); (2) hydrolysis of the ES used (with more than 2 phosphorus atoms in a molecule); (3) possible changes in the forms of binding of the salts present and thus a change in their dissociative characteristics; and (4) polymorphism of dairy fat and a gradual change of its crystal form (Carić and Kaláb, 1997; Muslow et al., 2007; Shirashoji et al., 2010).

\section{CONCLUSIONS}

The aim of the study was to observe texture parameters of model samples of processed cheese with the addition of ternary mixtures containing DSP, TSPP, and polyphosphate with different mean lengths $(\mathrm{n} \approx$ $5,9,13,20$, and 28). In the second part, TSPP was replaced with PSTP. The samples were made without and with $\mathrm{pH}$ adjustment (to achieve $\mathrm{pH}$ values typical of processed cheese spreads). The influence of the ternary mixture composition on the dispersion of casein micelles was also observed in the model milk system. With a low content of polyphosphate, hardness of the processed cheese increased and cohesiveness and relative adhesiveness decreased at a ratio of DSP to TSPP around 1:1 to 3:4. An increasing amount of polyphosphate (in the ternary mixture) led to a decrease in hardness of the processed cheese at this specific ratio. With the relative amount of polyphosphates reaching $\geq 60 \%$, the influence of this specific ratio became insignificant. This trend was observed in all ternary mixtures; the only differences were found in the absolute values of texture parameters of the processed cheeses. Replacing TSPP with PSTP did not affect the general trend either. However, the absolute values of hardness of model samples with the addition of PSTP were lower compared with the usage of TSPP. Duration of the storage period increased hardness of the processed cheeses. In the samples where $\mathrm{pH}$ was intentionally increased, hardness and cohesiveness decreased and relative adhesiveness increased slightly. The reverse 
trend was observed in samples in which $\mathrm{pH}$ was decreased. The more significant the $\mathrm{pH}$ adjustment, the more noticeable the changes observed. However, $\mathrm{pH}$ adjustment did not affect the value of the specific ratio of DSP:TSPP and DSP:PSTP and its general influence on texture parameters of the processed cheeses. The influence of the specific ratio of DSP:TSPP and DSP:PSTP and the general trend concerning the dependence of composition of the ternary mixtures of phosphate ES on the texture parameters of processed cheeses cannot be attributed only to the effect of phosphates on the dispersion of casein structures in the melt. During the creaming process, other interactions occur that affect the final form of the casein matrix.

\section{ACKNOWLEDGMENTS}

This study was supported by a project of the internal grants of Tomas Bata University (Zlín, Czech Republic; no. IGA/FT/2012/026 and IGA/FT/2013/010) funded from the resources for specific university research.

\section{REFERENCES}

Awad, R. A., L. B. Abdel-Hamid, S. A. El-Shabrawy, and R. K. Singh 2002. Texture and microstructure of block type processed cheese with formulated emulsifying salt mixtures. Lebenson. Wiss. Technol. 35:54-61.

Bayarri, S., I. Carconell, and E. Costell. 2012. Viscoelasticity and texture of spreadable cheeses with different fat contents at refrigeration and room temperatures. J. Dairy Sci. 95:6926-6936.

Brickley, C. A., S. Govindasamy-Lucey, J. J. Jaegii, M. E. Johnson, P. L. H. McSweeney, and J. A. Lucey. 2008. Influence of emulsifying salts on the textural properties of nonfat process cheese made from direct acid cheese bases. J. Dairy Sci. 91:39-48.

Buňka, F., L. Doudová, E. Weiserová, D. Kuchař, J. Michálek, Š Slavíková, and S. Kráčmar. 2012. The effect of different ternary mixtures of sodium phosphates on hardness of processed cheese spreads. Int. J. Food Sci. Technol. 47:2063-2071.

Buňka, F., L. Doudová, E. Weiserová, D. Kuchař, P. Ponížil, D Začalová, G. Nagyová, V. Pachlová, and J. Michálek. 2013. The effect of ternary emulsifying salt composition and cheese maturity on the textural properties of processed cheese. Int. Dairy J. $29: 1-7$.

Carić, M., and M. Kaláb. 1997. Processed cheese products. Pages 467-505 in Cheese: Chemistry, Physics and Microbiology. Vol. 2. Major Cheese Groups. 2nd ed. P. F. Fox, ed. Chapman \& Hall, London, UK.

Cunha, C. R., R. Grimaldi, M. R. Alcântara, and W. H. Viotto. 2013. Effect of the type of fat on rheology, functional properties and sensory acceptance of spreadable cheese analogue. Int. J. Dairy Technol. 66:54-62.

Cunha, C. R., and W. H. Viotto. 2010. Casein peptization, functional properties, and sensory acceptance of processed cheese spreads made with different emulsifying salts. J. Food Sci. 75:C113-C120.

Dimitreli, G., and A. S. Thomareis. 2009. Instrumental textural and viscoelastic properties of processed cheese as affected by emulsifying salts and in relation to its apparent viscosity. Int. J. Food Prop. 12:261-275.
El-Bakry, M., E. Duggan, E. D. O'Riordan, and M. O'Sullivan. 2011. Effect of chelating salt type on casein hydration and fat emulsification during manufacture and post-manufacture functionality of imitation cheese. J. Food Eng. 102:145-153.

Guinee, T. P., M. Carić, and M. Kaláb. 2004. Pasteurized processed cheese and substitute/imitation cheese products. Pages 349-394 in Cheese: Chemistry, Physics and Microbiology 2. 3rd ed. P. F. Fox, P. L. H. McSweeney, T. P. Cogan, and T. Guinee, ed. Elsevier Applied Science, London, UK.

Horne, D. S. 1998. Casein interactions: Casting light on the black boxes, the structure in dairy products. Int. Dairy J. 7:171-177.

ISO (International Organization for Standardization). 2004. ISO Standard No. 5534: Cheese and processed cheese-Determination of the total solids content (reference method). ISO, Geneva, Switzerland.

Kaliappan, S., and J. A. Lucey. 2011. Influence of mixtures of calcium-chelating salts on the physicochemical properties of casein micelles. J. Dairy Sci. 94:4255-4263.

Kapoor, R., L. E. Metzger, A. C. Biswan, and K. Muthukummarappan. 2007. Effect of natural cheese characteristics on process cheese properties. J. Dairy Sci. 90:1625-1634.

Kawasaki, Y. 2008. Influence of "creaming" on the properties of processed cheese and changes in the structure of casein during cheese making. Milchwissenschaft 63:149-153.

Lee, S. K., S. Anema, and H. Klostermeyer. 2004. The influence of moisture content on the rheological properties of processed cheese spreads. Int. J. Food Sci. Technol. 39:763-771.

Lee, S. K., and H. Klostermeyer. 2001. The effect of pH on the rheological properties of reduced-fat model processed cheese spreads. Lebenson. Wiss. Technol. 34:288-292.

Lu, Y., N. Shirashoji, and J. A. Lucey. 2008. Effects of pH on the textural properties and meltability of pasteurized process cheese made with different types of emulsifying salts. J. Food Sci. 73:E363E369.

Macků, I., F. Buňka, V. Pavlínek, P. Leciánová, and J. Hrabě. 2008. The effect of pectin concentration on viscoelastic and sensory properties of processed cheese. Int. J. Food Sci. Technol. 43:16631670 .

Marchesseau, S., E. Gastaldi, A. Laguade, and J.-L. Cuq. 1997. Influence of $\mathrm{pH}$ on protein interactions and microstructure of process cheese. J. Dairy Sci. 80:1483-1489.

Mizuno, R., and J. A. Lucey. 2005a. Effects of emulsifying salts on the turbidity and calcium-phosphate-protein interactions in casein micelles. J. Dairy Sci. 88:3070-3078.

Mizuno, R., and J. A. Lucey. 2005b. Effects of two types of emulsifying salts on the functionality of nonfat pasta filata cheese. J. Dairy Sci. 88:3411-3425.

Mizuno, R., and J. A. Lucey. 2007. Properties of milk protein gels formed by phosphates. J. Dairy Sci. 90:4524-4531.

Muslow, B. B., D. Jaros, and H. Rohm. 2007. Processed cheese and cheese analogues. Pages 210-235 in Structure of Dairy Products. Blackwell Publishing Ltd., Ames, IA.

Sádlíková, I., F. Buňka, P. Budínský, B. Voldánová, V. Pavlínek, and I. Hoza. 2010. The effect of selected phosphate emulsifying salts on viscoelastic properties of processed cheese. Lebenson. Wiss. Technol. 43:1220-1225.

Shirashoji, N., J. J. Jaeggi, and J. A. Lucey. 2006. Effect of trisodium citrate concentration and cooking time on the physicochemical properties of pasteurized process cheese. J. Dairy Sci. 89:15-28.

Shirashoji, N., J. J. Jaeggi, and J. A. Lucey. 2010. Effect of sodium hexametaphosphate concentration and cooking time on the physicochemical properties of pasteurized process cheese. J. Dairy Sci. 93:2827-2837.

Weiserová, E., L. Doudová, L. Galiová, L. Žák, J. Michálek, R. Janiš, and F. Buňka. 2011. The effect of combinations of sodium phosphates in binary mixtures on selected texture parameters of processed cheese spreads. Int. Dairy J. 21:979-986. 